\title{
The Effects of Low Power Laser Therapy on Muscle Healing Following Acute Blunt Trauma
}

Brian D. Fisher, Ph.D., Sandy Rennie, MSc, Pt, Sharron Warren Ph.D., David Magee Ph.D., PT, JAe Кoh MSc

Department of Physical Education and Recreation, University of Alberta: Edmonton, Alberta, Canada T6G 2H9. FAX +1 780-492-2364

\begin{abstract}
Many forms of treatment are utilized by physiotherapists for the treatment of soft tissue injuries. One of these is the use of low powered laser (LPLT). The purpose of this study was to determine the effects of LPLT $\left(\mathrm{lj} / \mathrm{cm}^{2}\right.$, daily 10$)$ on acute blunt trauma to muscles in controlled animal experiments. A reproducible model of single acute blunt trauma to the lower leg muscles of anaesthetized male rats $(n=28)$ was used. The level of contractile protein content and collagenous protein content were determined 12 days post-trauma in control, injured, laser-control and laser treated animals. Our data demonstrated an overall decrease in the levels of contractile protein content, in the various groups, which were not statistically different ( $p>0.05)$, and an overall significant increase in the levels of collagenous protein content $(\mathrm{p}<0.005)$. It was concluded that the LPLT protocol used for the recovery of injured muscle was not of significant benefit during the time period employed in this study (day 3 to day 12 posttrauma) following acute blunt trauma. The data confirmed a decrease in the levels of contractile proteins and an increase in the levels of collagenous proteins in muscle following injury.
\end{abstract}

Key words: Skeletal muscle, Low power laser, Trauma, Rat.

(This article was submitted Dec. 6, 1999, and was accepted Mar. 20, 2000)

\section{INTRODUCTION}

Soft tissue injury resulting from a single blow or crush is common ${ }^{1)}$ and laser therapy has become a frequently used modality by physical therapists in the management of this type of trauma ${ }^{2}$. Lasers are reported to act by the inhibition or stimulation of biochemical, physiological, and proliferative activities of cells and tissues. However, the magnitude of these responses is also determined by the wavelength and dosage of the laser light ${ }^{3}$.

The main constituents of muscle fibres are proteins, which undergo continual breakdown and replacement ${ }^{4)}$. When skeletal muscle is traumatized, localized degeneration is followed by regeneration. The degenerative process is initiated at the time of injury by inflammatory mediators such as eicosanoids, which induce a catabolic response. The acute degenerative phase lasts for approximately 3 days. The regenerative phase then commences and continues until day 21 post-injury ${ }^{5,6)}$.

Within the belly of each muscle there is a connective tissue component which forms the perimysium and endomysium. Both collagen and elastin provide a flexible scaffold to which the contractile proteins of the muscle are anchored ${ }^{7}$. Following muscle injury two processes compete, namely the regeneration of the damaged muscle and the production of a connective tissue scar8). The formation of excessive scar tissue may lead to the formation of a mechanical barrier which inhibits muscle regeneration ${ }^{4}$. For a therapeutic modality to be effective it should reduce the acute inflammatory response and accelerate the recovery phase, so that muscle regeneration is enhanced rather than scar formation. Animal studies on laser therapy have shown positive results in relation to the healing of soft tissue wounds ${ }^{9,10)}$. The cellular 
basis for the laser-initiated response still requires full explanation; however, one report ${ }^{11)}$ has speculated that stimulation of the respiratory chain is a possible mechanism ${ }^{12)}$. Basford ${ }^{13)}$ showed that the penetration and absorption values for laser beams depend on wavelength, and that infrared radiation is more effective for the therapy of acute inflammation, whereas helium-neon irradiation is more effective in relation to repair and tissue recovery. The clinical effectiveness of laser therapy on the acute inflammation which follows blunt injury has yet to be examined in detail. One study has shown that the release of prostaglandins is increased from tissues treated with low power laser ${ }^{14)}$. Also, enhanced phagocytosis by macrophages, and increases in lymphocytes and in blood flow have been reported ${ }^{15,16)}$.

A number of reports on the clinical use of low power laser (LPL) therapy following injury are available ${ }^{10,14,17,18)}$. However, the effects of this therapeutic modality on traumatized skeletal muscle remain to be fully evaluated, particularly at the cellular level. It is important that physical therapists be provided with information concerning the applicability and effectiveness of the therapeutic modalities which they use. In order to generate such data, an animal model (laboratory rat) and a standardized injury device capable of producing a single impact injury that approximates a muscle contusion ${ }^{19)}$ were used in the present study.

The purpose of this controlled experimental study was to determine the effects of a therapeutic dosage of laser in the treatment of acute blunt muscle trauma.

\section{METHODS}

\section{Subjects}

All the procedures carried out were in accordance with the guiding principles for the care and use of laboratory animals of the Canadian Council on Animal Care (CCAC), published in 1988. Twenty-eight male rats (Sprague Dawley strain) were used. The initial body weight of the rats ranged from 200 to 250 grams. The animals were housed in twelve standard wire cages, in groups of two or three of approximately the same weight, to decrease the chances of conflict among them. Commercial Rat Chow and water were provided ad libitum. The animals were kept on a 12 hour light to 12 hour dark cycle. The animals also were weighed prior to sacrifice to determine if there were any significant differences in their body weights which could be related to muscle trauma or to the LPLT used in the study.

\section{EXPERIMENTAL TRAUMA}

\section{Trauma Device}

A single impact trauma was delivered to the medial aspect of the calf of the right leg, as described previously by Fisher et al.6) During the procedure, rats were briefly anaesthetized with halothane; control rats were also anesthetized to ensure standardisation. The trauma was produced by dropping a solid aluminum bar with a flat surface $(1.38 \mathrm{~cm}$ in diameter, weighing $700 \mathrm{~g})$ down a tubular guide through a distance of $125 \mathrm{~mm}$ onto the medial gastrocnemius muscle. The force delivered by the device was $0.57 \mathrm{~N} . \mathrm{n} / \mathrm{cm}^{2}$; the moment of impact was $1099 \mathrm{~kg} . \mathrm{m} / \mathrm{s}$.

\section{Laser Therapy}

The animals received $1 \mathrm{~J} / \mathrm{cm}^{2}$ of energy density through a probe tip of $0.01 \mathrm{~cm}^{2}$ (Lazer-Train Unit). This dosage was selected to coincide with the clinical regimes most commonly used as judged by an informal inquiry of members of the Canadian Physical Therapy Association who are treating soft tissue injuries, and from a review of the literature ${ }^{2,20)}$. The laser unit was turned on for approximately 11.1 seconds for each of the two loci treated, in order to deliver the programmed amount of energy and achieve biostimulative effects in deep tissues, as suggested by earlier investigators ${ }^{10,20)}$. The treatment commenced on day 3 following trauma, and was given daily up to and including day 12 , on a once per day basis, at the same time each day. According to other investigators ${ }^{21)}$, acute blunt trauma may be followed by muscle protein wasting or loss. Such loss has been observed in the first three days following trauma, and thereafter there is muscle protein repletion ${ }^{6}$.

\section{Study Design}

The rats were divided in groups as follows: Groups I and II were control groups and Groups III and IV were treatment groups. Group I was composed of control uninjured animals that received no treatment; Group II was composed of injured animals that received no treatment; Group III was composed of uninjured animals that were laser 
treated; and Group IV was composed of injured animals that were laser treated.

\section{Analysis of Data}

The purpose of this study was to determine the effects of Low Power Laser Therapy (LPLT) on skeletal muscle following acute blunt trauma. The effects of LPLT upon non-collagenous (contractile) proteins and collagenous protein of muscle were measured in the four groups of rats, and twoway analysis of variance was used to determine if there were any significant differences in results. A $P$ value $>0.05$ was considered to be significant. In order to identify significant differences, post hoc comparisons were made (Scheffe), (see Table 1). The data were described in terms of means, standard deviations and standard errors of the mean.

\section{RESULTS}

\section{Non-Collagenous Protein Content (contractile pro- teins)}

In order to assess the effects of LPLT on skeletal muscle following injury, observations were made on the four groups of rats. As shown in Table 2 (Two Way Anova, P>.05) (Post Hoc comparisons with means and standard deviations), no significant differences were found in the non-collagenous protein content of the medial gastrocnemius muscle

Table 1. Two Way Anova Summary for non-collagenous (contractile) protein content of the medial gastrocnemius muscle ${ }^{22)}$

\begin{tabular}{lccc}
\hline \multicolumn{1}{c}{ Source } & M.S & F-Ratio & Prob. \\
\hline Injury & 19919.274 & 1.436 & 0.256 \\
Laser & 0 & 0 & 1 \\
Injury and Laser & 0 & 0 & 1 \\
\hline
\end{tabular}

among the groups. There appeared to be a decrease in the non-collagenous protein content of the same muscle in control injured animals (Group II) as compared to control uninjured animals (Group I) following the twelve day post-trauma period of the study. There was no significant difference between the muscle content of non-collagenous protein in control injured animals (Group II) and in laser-treated-injured animals (Group IV), as shown in Table 2. This finding indicates that LPLT did not increase the level of non-collagenous protein in traumatized muscle. Indeed, the lasertreated injured animals (Group IV) had a lower content of non-collagenous protein than the control uninjured animals (Group I), control-injured animals (Group II), and laser-treated uninjured animals (Group III).

No significant difference was found in the muscle content of non-collagenous protein between control uninjured animals (Group I) and lasertreated uninjured animals (Group III) (Table 2). Notwithstanding the lack of statistically significant differences among the groups studied, LPLT applied to uninjured animals (Group III) appeared to inhibit the synthesis of non-collagenous protein. The results in Table 2 show that the levels of noncollagenous protein were lower in the laser-treated groups than in the untreated groups.

\section{Collagenous Protein Content (non-contractile protein)}

There was a significant increase in the collagenous protein content in control injured muscle (Group II) in comparison to control uninjured muscle (Group I) as shown in Table 3 (Two Way Anova, P>.05) and Table 4 (Post Hoc comparisons with means and standard deviations).

LPLT applied to hind limbs of injured animals (Group IV) apparently increased the content of col-

Table 2. Means, Standard Deviations (S.D) and Standard Errors of the Means (S.E.M) for non-collagenous protein content of the four groups studied. Post Hoc comparisons (Scheffe) were performed, but no differences were found. Obs: Values are in $\mathrm{ug} / \mathrm{mg}$ of dry tissue for the medial gastrocnemius muscle.

\begin{tabular}{lcccc}
\hline & $\begin{array}{c}\text { Control } \\
\text { Non-Injured }\end{array}$ & $\begin{array}{c}\text { Control } \\
\text { Injured }\end{array}$ & $\begin{array}{c}\text { Laser } \\
\text { Non-Injured }\end{array}$ & $\begin{array}{c}\text { Laser } \\
\text { Injured }\end{array}$ \\
\hline Means & 495.85 & 466.85 & 430.14 & 372.14 \\
S.D & 70.53 & 89.63 & 90.87 & 184.97 \\
S.E.M & 26.71 & 33.95 & 34.42 & 70.06 \\
\hline
\end{tabular}


lagenous protein in comparison to the normal healing levels of control injured animals (Group II), but there was no significant difference between these two groups, as shown in Table 4. However, there was a significant difference between the group that was injured and received LPLT (Group IV) and the control uninjured animals in Group I, as shown in Table 4. Moreover, LPLT applied to injured hind limbs of animals (Group IV) increased their collagenous protein content in muscle in comparison to LPLT administered to uninjured animals (Group III) (Table 4). In addition, LPLT applied to uninjured animals (Group III) significantly increased $(\mathrm{p}<.005)$ the level of collagenous protein content in comparison to control uninjured animals (Group I) (Table 4).

\section{DISCUSSION}

\section{Low Power Laser Therapy for Muscle Trauma}

The dosage of LPLT chosen for this study was based on a consensus of current practice patterns by Canadian physiotherapists and a review of the literature; LPLT dosages still have not been standardized. Following injury, there is an inflammatory response which lasts from three to five days ${ }^{6,21,24)}$. At this stage, LPLT has been reported to increase macrophage activity ${ }^{18)}$, which enhances the recovery of the muscle. LPLT was

Table 3. Two Way Anova summary for collagenous protein content $^{23)}$ (see Appendix B)

\begin{tabular}{lccc}
\hline \multicolumn{1}{c}{ Source } & M.S & F-Ratio & Prob. \\
\hline Injury & 27.058 & 18.836 & 0.000 \\
Laser & 0.000 & 0.000 & 1.000 \\
Injury and Laser & -3.55 & 0.000 & 1.000 \\
\hline
\end{tabular}

applied from day 3 post-injury to day 12, that is during the fibroblastic phase of post-injury repair, which may last for weeks ${ }^{1,25)}$. According to the literature on soft tissue wounds $\left.{ }^{9}, 14\right)$, LPLT applied during this period induces an increase in the content of collagenous protein, which strengthens the healing wound.

It was hoped that LPLT would not induce fibroblastic proliferation to the point of replacing damaged muscle structures with non-functional scar tissue, but instead would lead to a proliferation of myoblasts and a reconstitution of damaged muscle. According to the present data, LPLT appears to have preferentially stimulated collagen production. However, it was not clear why LPLT did not enhance the non-collagenous protein content as well, because the energy delivered by the LPLT theoretically passed through and stimulated all layers of the muscle tissue.

In the initial catabolic response of muscle following trauma, proteins are broken down $6,21,26,27$, followed by an anabolic response with the formation of new muscle fibers and/or scar tissue, depending in part on whether the sarcolemma remains intact ${ }^{5}$. When the sarcolemma is torn during injury, there is subsequent infiltration of the muscle by fibroblasts with the production of collagen and the formation of a scar. According to the findings reported in the present study, LPLT appears to have preferentially stimulated fibroblasts to produce collagen. The fibroblasts likely already were proliferating and reproduced at a faster rate than the satellite cells and myoblasts responsible for muscle fiber regeneration ${ }^{5}$. The net outcome was an increased collagenous protein content leading to the formation of non-functional scar tissue.

Table 4. Means, Standard Deviations (S.D) and Standard Errors of the Means (S.E.M) for collagenous protein content of the four groups studied. Post Hoc comparisons (Scheffe) were performed and the group marked by a * was significantly different from the groups marked by **. Obs: Values are in $\mathrm{ug} / \mathrm{mg}$ of dry tissue.

\begin{tabular}{lcccc}
\hline & $\begin{array}{c}\text { I } \\
\text { Control } \\
\text { Non-Injured }\end{array}$ & $\begin{array}{c}\text { II } \\
\text { Control } \\
\text { Injured }\end{array}$ & $\begin{array}{c}\text { III } \\
\text { Laser } \\
\text { Non-Injured }\end{array}$ & $\begin{array}{c}\text { IV } \\
\text { Laser } \\
\text { Injured }\end{array}$ \\
\hline Means & $2.78^{*}$ & $5.04^{* *}$ & $4.28^{* *}$ & $5.29^{* *}$ \\
S.D & 0.35 & 1.14 & 0.40 & 0.56 \\
S.E.M & 0.13 & 0.43 & 0.15 & 0.21 \\
\hline
\end{tabular}


Non-Collagenous Protein Content

Muscle fibers are mainly composed of contractile proteins, which undergo continuous degradation and replacement ${ }^{4)}$. The balance of these two processes determines whether a muscle is undergoing atrophy or hypertrophy ${ }^{21)}$. Skeletal muscle tissue makes a large contribution to amino acid and protein metabolism ${ }^{27}$. In the catabolic response immediately following muscle trauma, the levels of non-collagenous (contractile) protein content in muscle are reduced $21,24,27$.

In the present study, the effects of the application of LPLT following acute blunt muscle trauma were determined. Previous results ${ }^{6}$ ) showed that non-collagenous protein content of muscle was reduced by $16 \%$ within 24 hours post-trauma, and that this reduction continued until day 3 posttrauma. The data from the present study did not show any significant differences between the contents of non-collagenous protein in muscle in the four groups of rats at 12 days post-trauma (Fig. 1). However, the non-collagenous protein content of the medial gastrocnemius muscles of control injured animals (Group II) appeared to be lower than those of control uninjured animals (Group I) at 12 days post-injury. Following the catabolic response due to trauma, muscles undergo an anabolic response. The non-collagenous protein content of muscles from injured animals only reaches pre-injury levels by 21 days post-injury ${ }^{6}$. In the present study, the non-collagenous protein content of the medial gastrocnemius muscles did not differ from those of uninjured animals. A possible explanation is that the peak anabolic response had not yet been reached by day 12 post-injury. The mean content of non-collagenous protein in muscle of control injured animals (Group II) was higher than that of the laser-treated injured animals (Group IV), but the foregoing was not significant ( $p>0.05)$, indicating that LPLT did not enhance the non-collagenous protein content of traumatized muscle (Fig. 1, Table 2) under the conditions of the study. It may be that the LPLT protocol employed resulted in an inhibition of the synthesis of non-collagenous protein. Perhaps the dosage of LPLT chosen was not the most appropriate. LPLT reduced the content of non-collagenous proteins in medial gastrocnemius muscles of uninjured animals (Group III). The lower content of non-collagenous proteins in the muscles of injured animals treated with LPLT may have been the result of competition for available

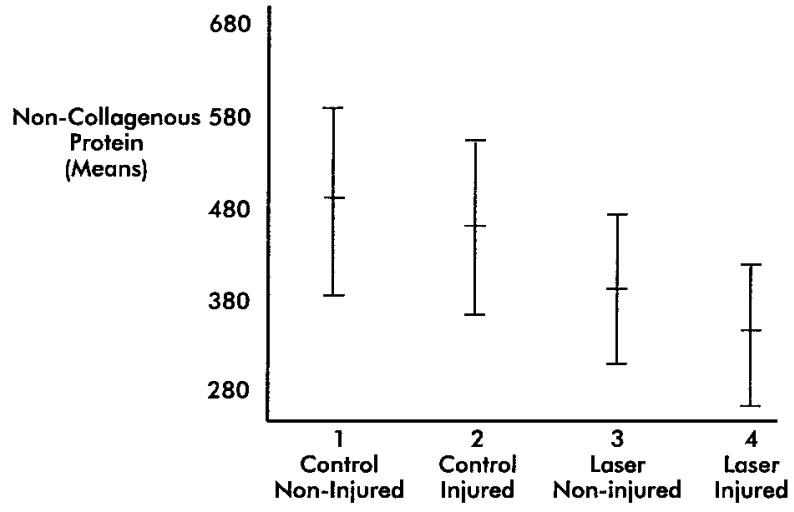

Fig. 1. Non-collagenous Protein Data for all Groups (Day 12 post-injury).

amino acids between collagenous and non-collagenous protein synthesis pathways that take place post-injury $8,28,29)$.

Muscle injuries are frequent among sports participants ${ }^{30)}$, and the extent and severity of damage is often difficult to measure. Inasmuch as LPLT is being employed as a therapeutic modality by physiotherapists to treat sports injuries ${ }^{31)}$, the present study was aimed at determining in an animal model the effectiveness of LPLT treatment following acute blunt muscle trauma. Our results demonstrate a general, but not statistically significant decrease in non-collagenous (contractile) protein content $(\mathrm{P}<0.05)$ in LPLT-treated medial gastrocnemius muscles.

The data for collagenous and non-collagenous muscle proteins showed opposite trends. Therefore, one is led to believe that LPLT following trauma under the conditions of this study was not beneficial because it favored the formation of non-functional collagenous scar in the muscle. However, only one treatment protocol was used, and only one timeframe relative to the injury was studied.

\section{Collagenous Protein Content}

From the present results it appeared that LPLT to injured animals (Group IV) induced higher levels of collagenous protein than were found in the other animal groups. A possible explanation for the increase in collagenous protein in the lasertreated injured animals (Group IV) may be the fact that these injured animals underwent a catabolic response due to the injury, followed by an anabolic response that preferentially activated the produc- 
tion of collagenous protein by fibroblasts, whereas animals in Group III that also received LPLT, had not suffered any injury. These data agreed with the data from control injured animals (Group II), but showed that LPLT to uninjured animals (Group III) still had an effect upon the collagenous protein content of muscle when compared with control uninjured animals (Group I) $(\mathrm{P}<0.005)$, rejecting the starting hypothesis of this study that LPLT to uninjured muscle has no effect upon the collagenous protein content.

According to Letho et al. ${ }^{32)}$, collagen production in traumatized muscle starts two days post-trauma, is most intense between days 5 and 21 , and decreases thereafter. The present study was confined to 12 days post-trauma. The data shown in Figure 2 and Table 4 indicate that injury causes an increase in the content of collagenous protein in the skeletal muscle when control injured rats (Group II) were compared to control uninjured rats (Group I) $(p<0.005)$. These data are in agreement with ultrastructural findings on the proliferation of fibroblasts at the site of injury6,32). When comparing control injured animals (Group II) and laser-treated injured animals (Group IV), no significant difference was found in the content of collagenous protein notwithstanding the tendency of LPLT to increase the level of collagen in muscle. LPLT increases the content of collagenous protein in injured rat muscle when compared to muscle undergoing unassisted healing. This tendency of LPLT to increase collagenous protein is not beneficial when an injured muscle is entering the anabolic phase of synthesis of contractile proteins. On the contrary, a greater increase in non-collagenous protein than in collagenous protein at 12 days post-trauma was expected. The literature has documented that LPLT increases the synthesis of collagen in healing soft tissue wounds ${ }^{9,14)}$. Considering the time-frame for treatment used in this study, the LPLT employed was not beneficial because, like the findings of Mester and Jaszsagi-Nagi ${ }^{10)}$, it adversely affected the quality of the healing process in the injured muscle. Perhaps the protocol used in the present study could be of benefit at a later stage (after the first three weeks post-trauma), following other conventional forms of treatment, such as ice, heat and then exercise.

Therefore, it appears that the dosage of LPLT and the period during which this modality is applied, have to be carefully selected to meet the requirements of various clinical conditions and the

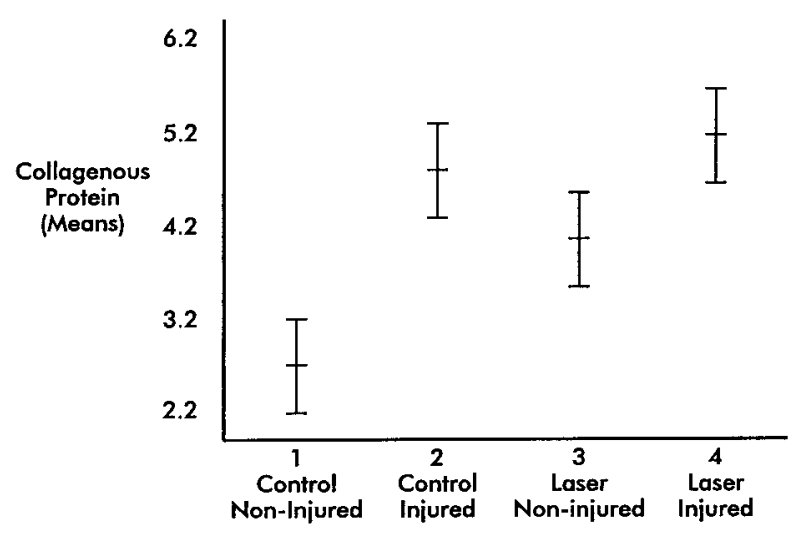

Fig. 2. Collagenous Protein Data for all Groups (Day 12 post-injury).

period during which this modality is applied.

Further studies are required to demonstrate the influence of early and late LPLT upon non-collagenous and collagenous protein contents and other functional characteristics of skeletal muscle tissue, following acute blunt trauma.

\section{REFERENCES}

1) Gould III JA: Orthopaedic and Sports Physical Therapy, C.V. Mosby Company, 2nd Edition. 1990, St. Louis.

2) Michlovitz S: Thermal Agents in Rehabilitation, 1996, FA Davis Co., Philadelphia, pp 256-274.

3) Beckerman H, Bouter R, De Cuyper H: The efficacy of laser therapy for musculoskeletal and skin disorders: a criteria-based meta-analysis of randomized clinical trials. 1992, Physical Therapy 72: 483-491.

4) Carlson B: The satellite cell and skeletal muscle regeneration. A review. In Repetitive Motion Disorders of The Upper Extremity. 1996, American Academy of Orthopaedic Surgeons: 313-322.

5) Engel GA, Banker BQ: Myology, 1986, McGraw Hill Book Company, New York, Vol I.

6) Fisher BD, Baracos VE, Shnitka TK, et al.: Ultrastructural events following acute muscle blunt trauma. 1990, Medicine and Science in Sports and Exercise 15: 185-193.

7) Stauber W: Repair models and specific tissue response in muscle injury in sports induced inflammation. 1990, American Academy of Orthopaedic Disease: 205-215.

8) Letho M, Duance VC, Restall D: Collagen and fibronectin in a healing skeletal muscle injury. An immunohistological study of the effects of physical activity on the repair of injured gastrocnemius muscle in the rat. 1985, Journal of Bone and Joint Surgery (Br) 67B: 820-827. 
9) Lyons RF, Abergel RP, White RA, et al.: Biostimulation of wound healing in vivo by a heliumneon laster. 1987, Annals of Plastic Surgery 18: 47-50.

10) Mester E, Jaszsagi-Nagi E: The effects of laser radiation on wound and collagen synthesis. 1973, Studia Biophysica 35: 227-230.

11) Karu R: Photobiological fundamentals of low power laser therapy. 1987, IEEE Journal of Qauntum Electron Vol QE23: 10.

12) Passarella $S$, Casamassima E, Molinari S, et al.: Increase of proton electrochemical potential and ATP synthesis in rat liver mitochondria irradiated in vitro by Helium-Neon laser. 1984, FEBS Letters 175 (1): 95-99.

13) Basford J: Low-energy laser therapy: Controversies and new research findings. 1989, Lasers in Surgery and Medicine 9: 1-5.

14) Mester E, Mester A: A Data for Biostimulation in Wound-Healing, Laser optoelectronics in medicine, 1988, Springer-Verlag, Berlin, 731-735.

15) Glassberg E, Lask G, Uitto J: Biological effects of low energy laser irradiation. 1988, Lasers in Surgery and Medicine (abstract) 8: 186.

16) Lievens P: The influence of laser on the lymphatic system. 1988, Lasers in Surgery and Medicine (abstract) 8: 175-176.

17) Kahn J: Case report: open wound management with $\mathrm{NeNe}$ (6328 AU) cold laser. 1984, Journal of Orthopaedic and Sports Physical Therapy 6 (3): 203-204.

18) Enwemeka CS: Laser bio-stimulation of healing wounds: Specific effects and mechanisms of action. 1988, Journal of Orthopaedic and Sports Physical Therapy 9 (10): 333-338.

19) Stratton SA, Heckmann R, Francis RS: Therapeutic ultrasound, its effects on the integrity of a non-penetrating wound. 1984, Journal of Orthopaedic and Sports Physical Therapy 5: 278-281.

20) Castel MF: A Clinical Guide to Low Power Laser Therapy, 1985, Physiotechnology Ltd., Downsview, Ontario, Canada.
21) Tischler ME, Fagan JM: Response to trauma of protein, amino acid and carbohydrate metabolism in injured and uninjured rat skeletal muscles. 1983, Metabolism 32: 853-868.

22) Lowry O, Rosebrough N, Fow A: Protein measurement with the folin phenol reagent. 1951, Journal of Biological Chemistry 193: 265-275.

23) Woessner JF: The determination of hydroxyproline in tissue and protein samples containing small proportions of this amino acid. 1961, Archives of Biochemistry and Biophysics 93: 440-447.

24) Fisher BD, Baracos VE, Reid DC: Effect of systematic inhibition of prostaglandins synthesis on muscle protein balance after trauma in the rat. 1991, Canadian Journal of Physiology and Pharmacology 69: 831-836.

25) Rubin E, Farber J: Pathology, JB Lippincott C. 1986, Philadelphia, 1394-1414.

26) Carlson B, Faulkner JA: The regeneration of skeletal muscle fivers following injury. 1983, Medicine \& Science in Sports \& Exercise 15 (3): 187-198.

27) Rennie MJ, Goldberg AL: Arachidonic acid, prostaglandins E2 and F2 influences rates of protein turnover in skeletal and cardiac muscle. 1982, Journal of Biological Chemistry 25: 1632-1638.

28) Allbrook D: Muscle regeneration. 1973, Physiotherapy, 59: 241-247.

29) Lieber R: Skeletal Muscle Structure and Function, 1992, Williams and Wilkins, Baltimore, pp 260-291.

30) Reed B, Zawrro V: Inflammation and repair and the use of thermal agents, In: Thermal Agents in Rehabilitation, Michlovita, S.L., Wolf, S.L. (Ed.), 1990, F.A. Davis Co., Philadelphia, 3-17.

31) Gordon SL, Bliar SJ, Fine LJ: Repetitive Motion Disorders of the Upper Extremity, 1994, American Academy of Orthopaedic Surgeons, Rosemont, Illinois.

32) Letho M, Jarvinen M, Nelimarkka O: Scar formation after skeletal muscle injury. A histological and autoradiographical study in rats. 1986, Archives of Orthopaedic and Trauma Surgery 104: 366-370. 